\title{
Development of Arginine Based Monopeptides as Cationic Surfactants from Pure Amino Acid
}

\author{
Pravin U. Singare ${ }^{1}$, Jyoti D. Mhatre,", \\ ${ }^{1}$ Department of Chemistry, Bhavan's College, Munshi Nagar, Andheri (West), 4000058, Mumbai \\ ${ }^{2}$ Department of Chemistry, Shri. Jagdishprasad Jhabarmal Tibrewala University, Jhunjhunu, 333001, Rajasthan \\ pravinsingare@gmail.com
}

\begin{abstract}
Amino acid-based surfactants constitute a class of cationic surfactants with excellent surface properties, wide biological activity, low potential toxicity. Essential structural factors for their antimicrobial activity include both the length of the fatty residue and the presence of the protonated guanidine function. These features and the use of natural raw materials such as Arginine and fatty acids for their synthesis, make them interesting candidates as preservatives and antiseptics in pharmaceutical, food and cosmetic formulations. The present work describes the synthesis (at lab scale), the physicochemical properties of long chain $\mathrm{N}^{\alpha}$-acyl arginine ethyl esters with a chain of 8 and 9 carbon atoms. These compounds have been prepared by condensation of L-arginine ethyl ester dihydrochloride with corresponding acyl chlorides in the presence of base. The basic charastristic properties such as physical appearance, structural identification by $\mathrm{IR} / \mathrm{H}^{1} \mathrm{NMR}$, water solubility at different $\mathrm{pH}$ and surface tension studies of the synthesized compounds are discussed. The Antimicrobial properties of the compounds of invention are studied by determin ing their Minimu m inhibitory concentration for different microorganisms.
\end{abstract}

Keywords Cationic Surfactants, $\mathrm{N}^{\alpha}$-Acyl, Arg inine, Schotten Baumann

\section{Introduction}

Surfactants are widely used in both consumer and industrial application, but they can adversely affect the environment. Therefore there is a growing demand for mild, biodegradable and nontoxic products that are made from natural raw materials. These surfactants can be obtained from molecules that mimic natural amphiphilic structures. The association of a polar amino acid (hydrophilic mo iety) and a non-polar long chain compound (hydrophobic moiety) to built amphiphilic structures allow obtaining molecules with a high surface activity.

Long chain $\mathrm{N}^{\alpha}$-acyl amino acids have been studied by many groups with the aim to obtain mild surfactants for preservative applications [1, 2]. Cationic surfactants derived from the condensation of fatty acids and esterified dibasic amino acids, such as from lauric acid and arginine, in particular the Et ester of the lauramide of the arginine monohydrochloride (LAE), may be used for the protection against the growth of the microorganisms. The cationic surfactants of this type are also effective against virus infections. Addition of LAE to cultures of Herpes virus type 1 Vaccinia virus and bovine parainfluenzae 3 virus leads to

* Corresponding author:

jyoti.mhatre27july@gmail.com (Jyoti D. Mhatre)

Published online at http://journal.sapub.org/scit

Copyright (C) 2012 Scientific \& Academic Publishing. All Rights Reserved nearly complete reduction of the virus organisms in these cultures, such effects being observed after 5 and $60 \min [3]$. Sugimoto and Toyoshima [4] have studied $\mathrm{N}^{\alpha}$-Cocoyl-L-Arg inine ethyl ester, DL-Pyroglutamic acid salt as an inactivator of Hepatit is B surface antigen. Lourdes et al[5], have synthesized a novel family of dicationic arginine -monoglyceride surfactants. Compounds having alkyl chain C10-C14 attached to the glycerol through esters and a dicationic polar head from the Arginine. An Article by Infante et al[6] studied the synthesis and properties of $\mathrm{N}^{\alpha}$-Lauroyl-L-Arginine dipeptides as methyl esters (cationic surfactants) and free $\alpha$-carboxylic acids (amphoteric surfactants). They found properties of these compounds are comparable to the cationic monomer derivatives methyl ester of $\mathrm{N}^{\alpha}$-Lauroyl-L-Arginine and of the amphoteric monomer derivative $\mathrm{N}^{\alpha}$-Lauroyl-L-Argin ine reported earlier. Seguer et al[7] also reported synthesis and physicochemical properties of $\mathrm{N}^{\alpha}$-acyl-L-argin ine dipeptides with a chain length between 8-16 carbon atoms. From the studies the author has summarized that the introduction of an appropriate long chain (14 carbon atoms) to the amino function of a mixture of amino acids yields an interesting multifunctional compound to be applied as soft preservative peptide surfactant in cosmetics, food and dermo-pharmaceu tical formulations.

Based on the studies done so far, it is clear that Essential structural factors for their antimicrobial activity include both the length of the fatty residue and the presence of the 
protonated guanidine function. These features and the use of natural raw materials such as Arginine and fatty acids for their synthesis, make them interesting candidates as preservatives and antiseptics in pharmaceutical, food and cosmetic formulations.

We were particularly interested in preparation of $\mathrm{N}^{\alpha}$-acyl argin ine esters ( $\mathrm{C} 8-\mathrm{Cl}$ ), which will be used as microbicide $\mathrm{s}$ in future. Microbicides are the group of pharmacologic agents and chemical substances that are capable of killing certain microorganis $m$ that commonly cause human infection by bacteria, fungi and viruses like HIV. In this paper we report the synthesis of $\mathrm{N}^{\alpha}$-Octanoyl and $\mathrm{N}^{\alpha}$-Nonanoyl-L-Agin ine ethyl ester by acylation of a basic amino acid with a positively charged side chain (arginine) and Octanoyl/Nonanoyl chlorides. The compounds are tested as antimicrobial agent against Gram-positive and Gram-Negative Bacteria.

\section{Chemistry}

With the aim to systematically study the influence of the alkyl chain length on the properties of long chain $\mathrm{N}^{\alpha}$-acyl arginine ethyl ester salts, we synthesized at multigram scale two pure homologues with alkyl chain of 8 (CAE) and 9 (NAE) carbon atoms (Fig. 1). The fatty residue, the guanidine basic residue and the protection of the carboxyl group in the molecule in the molecule of the arginine are essential structural factors for antimicrobial activity. The role of the alkyl chain length in the water solubility, surface activity, critical micellar concentration and antimicrobial activity of these compounds was examined in order to improve our understanding of the structure/properties relationship.

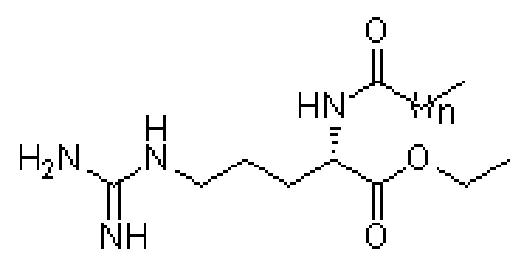

Figure 1. Molecular structure of the $\mathrm{N}^{\alpha}$-acyl arginine ethyl ester surfact ants; $n=6$ CAE, $n=7$ NAE, $n=10$ LAE

Solans et al[8,9] synthesized $\mathrm{N}^{\alpha}$-lauroyl argin ine methyl ester Hydrochloride (LAM), in gel emulsions of the system water $/ \mathrm{C}_{14} \mathrm{E}_{4} /$ decane and compared with those obtained in conventional dimethylformamide (DMF) media and found that LAM formation is faster in gel emulsions at short times. Clapes et al[10] have published a review where in enzy matic synthesis, physicochemical and biological properties as well as the potential uses of Amino-acid based surfactants are described. Rondel et al[11] have described the acylation of amino acids by acid chlorides with from 8-12 carbon atoms in alkaline aqueous medium following Schotten-Baumann reaction.

We have used an easy and very efficient procedure for the synthesis of the compounds of our interest. It consisted of three steps using L-Arginine as starting material. (1) Preparation of Fatty acid chloride (2) Synthesis of L-Arginine ethyl ester dihydrochloride by esterification process. (3) Synthesis of $\mathrm{N}^{\alpha}$-acyl arginine ethyl ester by acylation of $\alpha$-A mino group of L-Arginine ethyl ester dihydrochloride with the corresponding long chain acid chloride.

\section{Experimental Procedures}

\subsection{General Reagents and Syn thetic Method}

L-Arginine was purchased from Ajinomoto Co., Octanoic acid, Nonanoic acid and Sodium Dodecyl sulfate (SDS) were received from Sigma-Aldrich. LAE.HCl $\left(\mathrm{N}^{\alpha}\right.$-Lauroyl arginine ethyl ester Hydrochloride) was supplied by local supplier. Solvents used were of analytical grade or higher purity and supplied by Sigma-Aldrich. The homogeneity of compounds was checked by thin-layer chromatography on aluminium plates (Kieselgel G, Merck\}. The solvent systems were (A) chloroform/methanol/acetic acid (8.5:10:5 \}; and (B) chloroform/methanol (7:3). Ninhydrin developer solution was used for qualitative analysis of free amino groups.

Nuclear Magnetic Resonance ( ${ }^{1} \mathrm{H}$ NMR) and all the NMR measurements were performed with Bruker, Avance 300 spectrometer model at $300 \mathrm{MHz}$ in a $5 \mathrm{~mm}$ direct probe (BBO BB-1H) using $\mathrm{CDCl}_{3}$ as a solvent. Surface Tension was measured using Stalagmometer. Mass Spectroscopy with fast atom bombardment (FAB) was carried out with VG-QUATTRO from Fisons Instrument.

\section{Preparation of Fatty Acid Chl ori des}

In a four necked round bottom flask equipped with stirrer and thermo pocket charge 0.1 mole of Fatty Acid at room temperature and heat to $40^{\circ} \mathrm{C}$., then add $0.15 \mathrm{~mole}$ of Thionyl Chloride under Nitrogen atmosphere over a period of 1 hour and heat the reaction mixture to reflux for $1 \frac{1}{2}$ hour to obtain crude Acid Chloride.

Preparation of L-Arginine ethyl ester dihydrochloride In a $250 \mathrm{ml}$ round bottom flask charge Ethyl alcohol followed by the addition of L-Arginine free base. Stir vigorously to get a clear solution. Charge via addition funnel conc. $\mathrm{HCl}$ of $37 \%$ strength slowly controlling exotherm. Apply heat and reflux for 4-5 hours. Cool to 60 degree $\mathrm{C}$ and add more conc. $\mathrm{HCl}$ and reflux further till the completion of the reaction with simultaneous removal of ethanol. Apply vacuum and distill residual alcohol. Cool the residual mass to get crude L-Arginine ethyl ester dihydrochloride.

Preparation of Na-Acyl L-Arginine ethyl ester compounds by Schotten $B$ aumann reaction

The crude reaction product obtained in the first step is dissolved in water and the $\mathrm{pH}$ of the solution is brought to a specific $\mathrm{pH}$ value $5.5-7$ by the addition of aqueous sodium hydroxide. The $\mathrm{pH}$ of the reaction is carefully kept constant at this value until completion of the reaction. To this 
solution, add 0.96 equivalent of Octanoyl/Nonanoyl chloride drop-wise, whereby the temperature of the mixture is kept at a temperature of $10-15^{\circ} \mathrm{C}$ by means of an appropriate cooling bath containing ethylene glycol. After completion of the reaction, the stirring is maintained for a further two hours, after which the $\mathrm{pH}$ of the solution is adjusted to a final value of 5.5-7 with hydrochloric acid or sodium hydroxide. Finally, the crude reaction product is obtained either by filtration or by distillation.

Compound: Na-Octanoyl-L-Arginine ethyl ester (CAE) - Prepared by reaction between L-Arg inine Et ester diHCl and Octanoyl chloride in the presence of aqueous $\mathrm{NaOH}$. Clear Yellowish oil. MW 328, ESI-MS; m/z $329\left(\mathrm{~m}^{+}\right) ;{ }^{1} \mathrm{H}$ NMR: $\delta_{\mathrm{H}}\left(\mathrm{CDCl}_{3}\right), 0.89\left[\mathrm{t}, 3 \mathrm{H},\left(\mathrm{CH}_{3}\right.\right.$ alkyl chain $\left.)\right], 1.29[\mathrm{~s}$, $11 \mathrm{H},\left(4 \mathrm{CH}_{2}\right.$, alkyl chain $\left.),\left(\mathrm{OCH}_{2}-\mathrm{CH}_{3}\right)\right], 1.5-1.7[\mathrm{~m}, 4 \mathrm{H}$,
$\left.\left(\mathrm{CH}_{2}-\mathrm{CH}_{2}-\mathrm{CO}-\mathrm{NH}-\right),\left(-\mathrm{CH}_{2}-\mathrm{CH}_{2}-\mathrm{CH}_{2}-\mathrm{NH}-\right)\right], 2.27[\mathrm{t}, 2 \mathrm{H}$, (NH-CH(COO) $\left.\left.-\mathrm{CH}_{2}-\mathrm{CH}_{2}-\right)\right], \quad 3.1-3.3\left[\left(-\mathrm{NH}-\mathrm{C}(=\mathrm{NH})-\mathrm{NH}_{2}\right)\right]$ 3.5-3.7[2H， (- $\left.\left.-\mathrm{CH}_{2}-\mathrm{CO}-\mathrm{NH}-\right)\right], 4.2\left[\mathrm{~m}, 2 \mathrm{H},\left(-\mathrm{OCH}_{2}-\mathrm{CH}_{3}\right)\right]$ $(-\mathrm{NH}-\underline{\mathrm{CH}}-\mathrm{COO}-)], 7.2\left[\mathrm{~s},\left(-\mathrm{NH}-\mathrm{C}(=\mathrm{NH})-\mathrm{NH}_{2}\right)\right]$ (See Figures 2 and 3 ).

Compound: Na-Nonanoyl L-Arginine ethyl ester (NAE) - Prepared by reaction between L-Argin ine Et ester $\mathrm{diHCl}$ and Nonanoyl chloride in the presence of aqueous $\mathrm{NaOH}$. Light brown sticky mass. MW 342, ESI-MS; m/z $343\left(\mathrm{~m}^{+}\right) ;{ }^{1} \mathrm{H}$ NMR: $\delta_{\mathrm{H}}\left(\mathrm{CDCl}_{3}\right), 0.87\left[\mathrm{t}, 3 \mathrm{H},\left(\mathrm{CH}_{3}\right.\right.$ alkyl chain)], $1.27\left[\mathrm{~s}, 10 \mathrm{H}, 5 \mathrm{CH}_{2}\right.$, alkyl chain], $1.59-1.83[\mathrm{~m}, 4 \mathrm{H}$, $\left.\left(\mathrm{CH}_{2}-\mathrm{CH}_{2}-\mathrm{CO}-\mathrm{NH}-\right),\left(-\mathrm{CH}_{2}-\mathrm{CH}_{2}-\mathrm{CH}_{2}-\mathrm{NH}-\right)\right], 2.27[\mathrm{t}, 2 \mathrm{H}$, $\left.\left(-\mathrm{CH}_{2}-\mathrm{CO}-\mathrm{NH}-\right)\right], \quad 4.2\left[\mathrm{~m}, 2 \mathrm{H},\left(-\mathrm{OCH}_{2}-\mathrm{CH}_{3}\right), 4.42[\mathrm{~m}, 1 \mathrm{H}\right.$, $(-\mathrm{NH}-\underline{\mathrm{CH}}-\mathrm{COO}-), 7.26\left[\left(-\mathrm{NH}-\mathrm{C}(=\mathrm{NH})-\mathrm{NH}_{2}\right)\right]$ (See Figures 4 and 5).

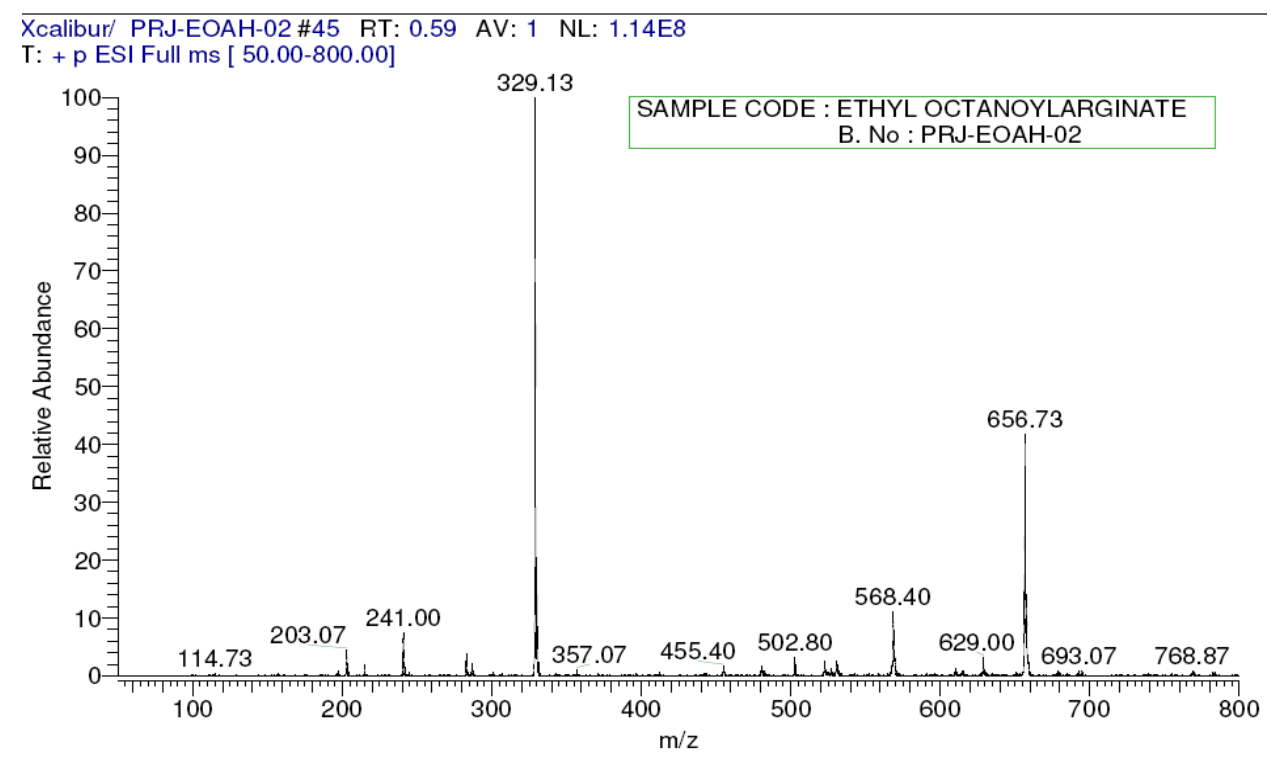

Figure 2. Mass spectrum of $\mathrm{N} \alpha$-Octanoyl-L-Arginine ethyl ester

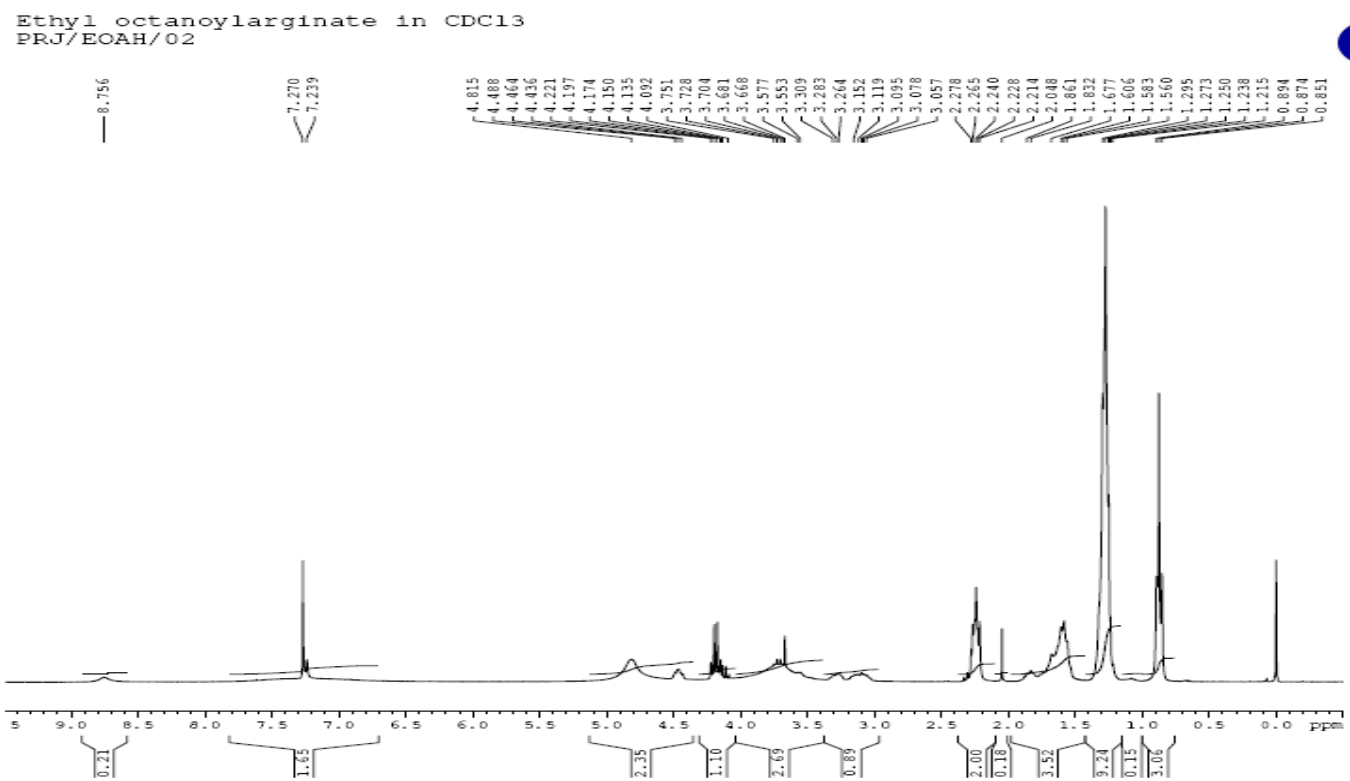

Figure 3. Proton NMR of N $\alpha$-Octanoy l-L-Arginine ethyl ester 


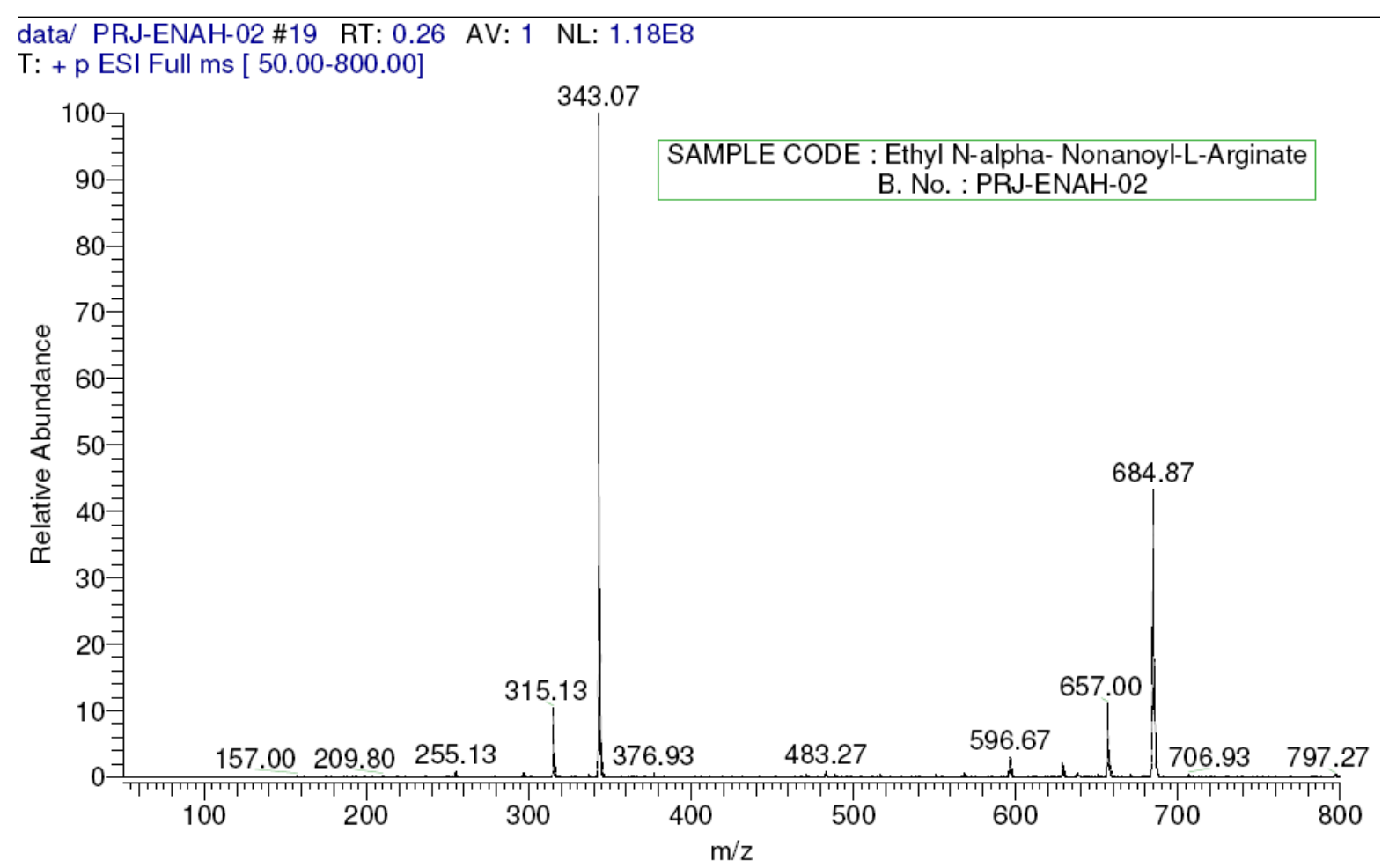

Figure 4. Mass spectrum of N $\alpha$-Nonanoyl-L-Arginine ethyl ester

Ethyl N-alpha-Nonanoyl-L-Arginate in CDCl3

B.NO.: PRJ/ENAH/O2

|

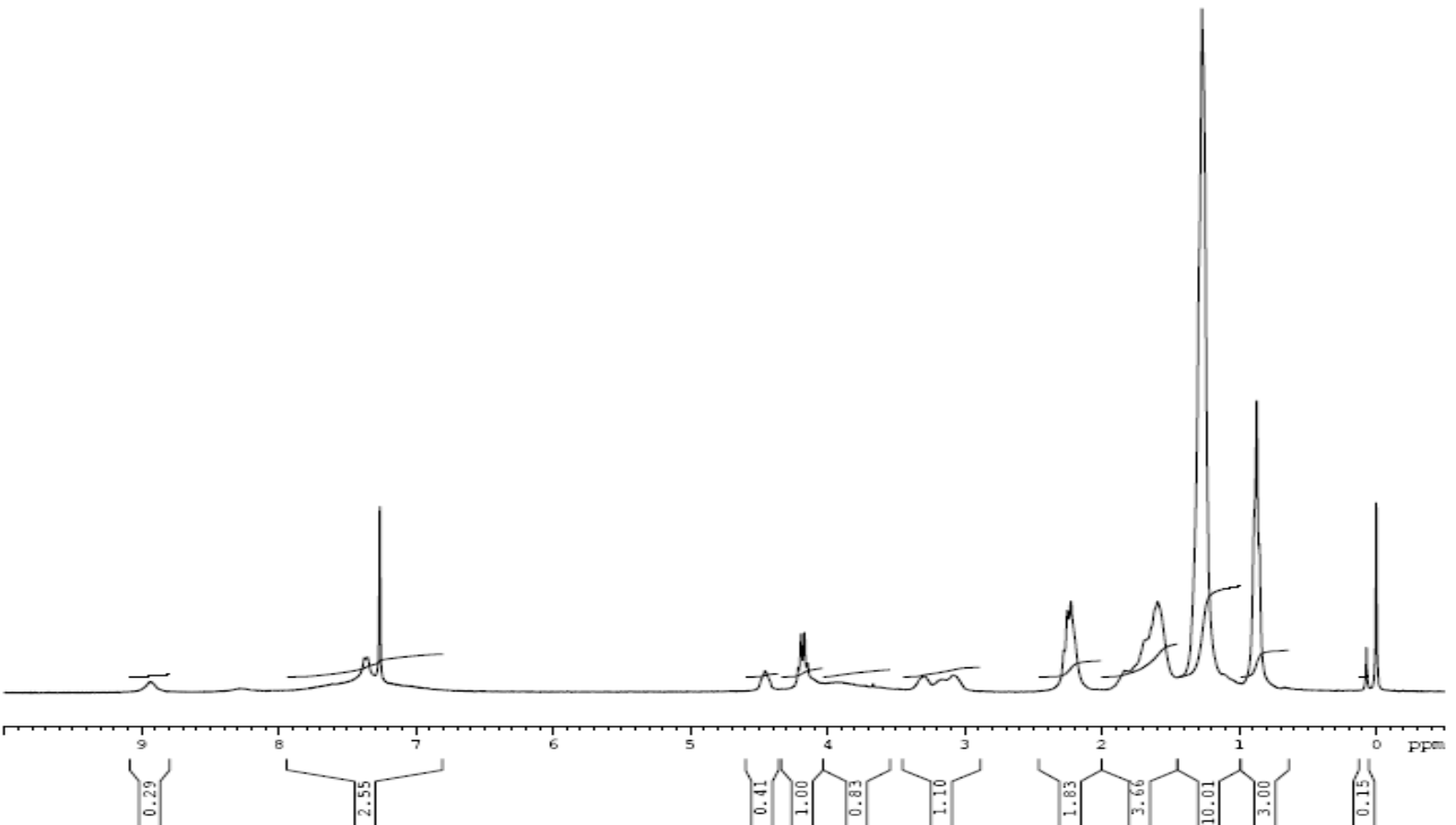

Figure 5. Proton NMR of N $\alpha$-Nonanoyl-L-Arginine ethyl ester 


\subsection{Analytical Methods}

The characteristic properties of the compounds synthesize $\mathrm{d}$ are summarized in Table 1. Their mass spectra showed only one mass peak corresponding to the molecular ion. The completion of reaction was monitored by TLC. Likewise, the ${ }^{1} \mathrm{H}$ NMR spectra of all compounds were in accordance with their proposed structure.

Table 1. Characteristic Properties of the Synthesized Compounds

\begin{tabular}{|c|c|c|c|c|}
\hline Comp. & Appearance & $\mathrm{Rf}$ & Mol. Formula & $\begin{array}{c}\mathrm{m} / \mathrm{e}\left[\mathrm{M}^{+}\right. \\
\mathrm{H}^{+}\end{array}$ \\
\hline $\begin{array}{c}\text { L-Arg.O } \\
\text { Et. diHCl }\end{array}$ & Sticky mass & 0.40 & $\mathrm{C}_{8} \mathrm{H}_{18} \mathrm{~N}_{4} \mathrm{O}_{2} .2 \mathrm{HCl}$ & --- \\
\hline CAE & $\begin{array}{c}\text { Clear Yellow } \\
\text { Oil }\end{array}$ & 0.68 & $\mathrm{C}_{16} \mathrm{H}_{32} \mathrm{~N}_{4} \mathrm{O}_{3}$ & 329 \\
\hline NAE & $\begin{array}{c}\text { Light brown } \\
\text { sticky } \\
\text { mass }\end{array}$ & 0.45 & $\mathrm{C} 17 \mathrm{H} 34 \mathrm{~N} 4 \mathrm{O} 3$ & 343 \\
\hline
\end{tabular}

The water solubility of CAE and NAE was partially studied at different $\mathrm{pH}$ values at a constant concentration of $1 \%(\mathrm{w} / \mathrm{v})$ and at room temperature. CAE is clear in the range of $\mathrm{pH} 2-11.5$, whereas solution of NAE is clear at $\mathrm{pH}$ 6-11, but insoluble at $\mathrm{pH} \leq 4$. This solubility data was compared with LAE solubility, which is showing clear solubility in the $\mathrm{pH}$ range 1-7.3 and insoluble at $\mathrm{pH}>8$ and $\leq 0.5$ (Table 2). These results appear to indicate that the insolubility increases with increase in chain length (Hydrophobic Character) of the compound.

Table 2. Water solubility of $1 \%$ aqueous solution at different $\mathrm{pH}$

\begin{tabular}{|c|c|c|c|}
\hline $\mathrm{pH}$ & CAE & NAE & LAE \\
\hline 1 & -- & $\mathrm{I}$ & $\mathrm{S}$ \\
\hline 2 & $\mathrm{~S}$ & $\mathrm{I}$ & $\mathrm{S}$ \\
\hline 4 & $\mathrm{~S}$ & $\mathrm{I}$ & $\mathrm{S}$ \\
\hline 7 & $\mathrm{~S}$ & $\mathrm{~S}$ & $\mathrm{~S}$ \\
\hline 8 & $\mathrm{~S}$ & $\mathrm{~S}$ & $\mathrm{I}$ \\
\hline 10 & $\mathrm{~S}$ & $\mathrm{~S}$ & $\mathrm{I}$ \\
\hline 11 & $\mathrm{~S}$ & $\mathrm{~S}$ & $\mathrm{I}$ \\
\hline
\end{tabular}

\subsubsection{Method for Surface Tension}

A tensiometer (Stalagmometer) with a Wilhelmy plate was used for surface tension measurements $(\gamma)$. Water /surfactant solutions of different concentrations were prepared and allowed to equilibrate at $25^{\circ} \mathrm{C}$ between 4 and $10 \mathrm{hr}$.

\subsubsection{Method for critical Micellar Concentration (CMC)}

The critical micellar concentration (CMC) was determine $\mathrm{d}$ fro $\mathrm{m}$ the break point of the surface tension /concentration curves.

\subsubsection{Antimic robial Activity}

Antimicrobial activity is tested by determining the Minimum Inhibitory concentration (MIC) of the compound of invention. MIC is defined as the lowest concentration of antimicrobial agent that inhibits the development of visible micro-organism growth after incubation at $32^{\circ} \mathrm{C}$ for $48 \mathrm{hrs}$ and fungal growth at $25^{\circ} \mathrm{C}$ for 4 days by Broth Dilution method. Sample was prepared by simply diluting $1 \mathrm{ml}$ of the $1 \%$ solution in DMSO with $9 \mathrm{ml}$ of broth Tryptic Soy Broth (1000ppm solution). This stock solution did not precipitate. From the above stock solution $1 \mathrm{ml}$ was added to each of 12 consecutive sterile $13 \mathrm{~mm}$ tubes containing $1 \mathrm{ml}$ TSB. Each tube is vortexed and asceptic transfer to give the below ppm. Each culture is grown in $\mathrm{TSB}>24 \mathrm{hrs}<48 \mathrm{hrs}$ at $32^{\circ} \mathrm{C}$. The culture is diluted to $10,000 \mathrm{cfu} / \mathrm{ml}$ and $10 \mu 1$ of this is added to each tube. Negative controls (NC) TSB confirm sterility of the TSB, Positive controls (PC) for each culture confirm organism capable of growth in the TSB.

\subsection{Results and Discussions}

Single chain Arg inine based surfactants have CMC values ca $1-10 \mathrm{mM}$ and these values decrease linearly as the number of methylene groups in the alkyl chain increases[12]. The high CMC values observed for the CAE are due to the fact that it has a less hydrophobic chain than that of LAE and NAE. In fact, a longer, more hydrophobic chain results in lower surface tension. The surface Tension and CMC values of CAE and NAE are compared against commercially available LAE and SDS (Table 3). The study indicates that both the values of surface tension and CMC are comparable and sometimes even lower than that of SDS. They therefore have interesting surface-active properties.

Table 3. Critical micellar concentration of $\mathrm{N}^{\alpha}$-acylarginine ester and references

\begin{tabular}{|c|c|c|}
\hline \multirow{2}{*}{ Compd. } & \multicolumn{2}{|c|}{ Appearance (in T ime New Roman or T imes) } \\
\cline { 2 - 3 } & CMC $(\mathrm{mg} / \mathrm{L})$ & $\gamma(\mathrm{mN} / \mathrm{m})$ \\
\hline CAE & $>1500$ & $27.0 \pm 0.5$ \\
\hline NAE & $820 \pm 50$ & $26.1 \pm 0.5$ \\
\hline LAE & $410 \pm 10$ & $25.5 \pm 0.5$ \\
\hline SDS & $290 \pm 30$ & 39.1 \\
\hline
\end{tabular}

Minimum inhibitory concentration (MIC) values for CAE and NAE compounds are summarized in Table 4. Comparis on of Minimum inhibitory concentration (MIC) values for CAE and NAE compounds with the MIC values of LAM indicates that (i) CAE is having low antimic robial activity against Staph. aureus, but Gram Negative bacteria are resistant to this surfactant. (ii) NAE shows almost same MIC values against Gram-positive and Gram-Negative bacteria, but is less active against C.albicans and A.niger.

In general, the antimicrobial activity of the surfactants depends on the alkyl chain length and the antimicrobial effect took place at concentrations of surfactant below the cmc. This suggests, in a good agreement with our results, that the antimicrobial activity is due to the individual molecules and not to the aggregates. For Medical applications, the use of cationic surfactants with low antimicrobial activity would be necessary based on their biodegradability and toxic ity data.

Further work is in progress in order to understand the influence of effect of chain length of fatty acid residue on the physicochemical properties and antimicrobial activities, to be able to assess the area of application of these materials. 
Table 4. Comparison of Minimum Inhibitory Concentration of LAM (Methyl Lauroylarginate), CAE and NAE in ppm

\begin{tabular}{|c|c|c|c|}
\hline \multirow{2}{*}{ Microorganism } & \multicolumn{3}{|c|}{ MIC (ppm) } \\
\cline { 2 - 4 } & CAE & NAE & LAM \\
\hline $\begin{array}{c}\text { Staphylococcus Aureus } \\
\text { AT CC 6538 }\end{array}$ & 500 & $62-125$ & 64 \\
\hline $\begin{array}{c}\text { Listeria Monocyt. ATCC } \\
751\end{array}$ & -- & $62-250$ & -- \\
\hline Escherichia Coli AT CC8739 & R & $62-125$ & 32 \\
\hline $\begin{array}{c}\text { Salmonella spp. ATCC } \\
10708\end{array}$ & -- & $62-250$ & 32 \\
\hline $\begin{array}{c}\text { Candida albicans ATCC } \\
10231\end{array}$ & R & $125-250$ & 64 \\
\hline $\begin{array}{c}\text { Aspergillus niger ATCC } \\
\text { 46604 }\end{array}$ & -- & $250 / 500-1000$ & 125 \\
\hline
\end{tabular}

\section{ACKNOWLEDGEMENTS}

We are indebted to Dr. Vilas Chopdekar and Dr. Richard Stockel for technical support to this project. We are also thankful to $\mathrm{V} \& \mathrm{~V}$ Pharma Industries for providing Laboratory to conduct experiments.

\section{REFERENCES}

[1] M. R. Infante, P. Erra, R. Juliá, M. Prats and J.J. Garcia Dominguez, "Surface active molecules: Preparation and properties of long chain $\mathrm{N} \alpha$-acyl-L- $\alpha, \omega$, guanidine alkyl acid derivatives," Int. J. Cosmet. Sci., vol. 6, pp. 275-282, (1984).

[2] M. R. Infante, J. Molinero, P. Bosch, P. Erra and R. Juliá, "Lip opeptidic surfactants. I. Neutral $\mathrm{N} \alpha$ lauroyl L-arginine dipeptides from pure amino acids," J. Am. Oil Chem. Soc., Vol. 66 (12), pp. 1835-1839, (1989).

[3] R. Bonvila, "Antiviral use of cationic surfactant," PCT Int. Appl. (2008), WO 2008014824
[4] Y. Sugimoto and S. Toyoshima, "N $\alpha$-Cocoyl-L-Arginine Ethyl Ester, DL-Pyroglutamic acid Salt, As an Inactivator of Hepatitis B surface Antigen," Antimicrobial Agent and Chemotherapy, vol.16 (3), pp. 329-332, Sept. 1979

[5] L. Pe'rez, A. Pinazo,M. T. Garci'a, M. del C. Mora' $n$ and M. R. Infante, "Monoglyceride surfactants from arginine: synthesis and biological properties," New J. Chem., vol. 28, pp. 1326-1334, (2004).

[6] M.R.Infante, J.Molinero and P. Erra, "Lipopeptidic surfactants. I. Acidic and Basic N $\alpha$ lauroyl L-arginine dipeptides from pure amino acids," J. Am. Oil Chem. Soc., Vol. 69 (7), pp. 647-652, (1992).

[7] J.Seguer, J. Molinero, A. Manresa, J. Caelles and M.R. Infante, "Physicochemical and antimicrobial properties of $\mathrm{N} \alpha$-acyl-L-arginine dipeptides from acid-hydrolyzed collagen, J. Soc. Cosmet. Chem., vol. 45, pp. 53-63, (1994).

[8] C. Solans, A. Pinazo, G. Calderó and M. R. Infante, "Highly concentrated emulsions as novel reaction media," Colloids and Surfaces A: Physicochemical and En gineering Aspects, vol. 176, pp. 101-108, (2001).

[9] A. Pinazo, M. R. Infante, P. Izquierdop and C. Solans, "Synthesis of arginine based surfactants in highly concentrated water-in-oil emulsions," J. Chem. Soc., Perkin Trans 2,pp. 1535-1539, (2000).

[10] P. Clapés and M. R. Infante, "Amino acid-based surfactants. Enzymatic Synthesis, properties and Potential Applications," Biocatalysis and Biotransformation, vol. 20 (4), pp. 215-233, (2002).

[11] C. Rondel, I. Alric, Z. Mouloungui, J. Blanco, F. Silvestre, "Synthesis and Properties of Lipoamino Acid-Fatty Acid Mixtures: Influence of the Amphiphilic Structure," J. Surfact. Deterg., vol. 12, pp. 269-275, (2009).

[12] C. Morán, P. Clapés, F. Comelles, T. Garcia, L. Pérez, P. Vinardell. M. Mitjans and M. R. Infante, "Chemical structure/property relationship in Single chain Arginine-based surfactants," Langmuir, vol. 17, pp. 5071-5075, (2001). 